\title{
Obesity and kidney disease
}

\author{
Obesidade e doença renal
}

\section{Authors}

Geraldo Bezerra da Silva Junior ${ }^{1}$

Ana Carla Sobral Novaes Bentes ${ }^{1}$

Elizabeth De Francesco

Daher ${ }^{2}$

Sheila Maria Alvim de Matos $^{3}$

${ }^{1}$ Universidade de Fortaleza.

${ }^{2}$ Universidade Federal do

Ceará.

${ }^{3}$ Universidade Federal da Bahia.
Submitted on: 6/13/2016. Approved on: 7/27/2016.

Correspondence to: Geraldo Bezerra da Silva Junior.

Universidade de Fortaleza UNIFOR.

Av Washington Soares, 1321, Bloco S, sala 1, Fortaleza, Ceará, Brazil. CEP: 60811-905 E-mail: geraldobezerrajr@ yahoo.com.br

DOI: 10.5935/0101-2800.20170011

\section{Abstract}

Obesity has been pointed out as an important cause of kidney diseases. Due to its close association with diabetes and hypertension, excess weight and obesity are important risk factors for chronic kidney disease (CKD). Obesity influences CKD development, among other factors, because it predisposes to diabetic nephropathy, hypertensive nephrosclerosis and focal and segmental glomerulosclerosis. Excess weight and obesity are associated with hemodynamic, structural and histological renal changes, in addition to metabolic and biochemical alterations that lead to kidney disease. Adipose tissue is dynamic and it is involved in the production of "adipokines", such as leptin, adiponectin, tumor necrosis factor- $\alpha$, monocyte chemoattractant protein-1, transforming growth factor- $\beta$ and angiotensin-II. A series of events is triggered by obesity, including insulin resistance, glucose intolerance, dyslipidemia, atherosclerosis and hypertension. There is evidence that obesity itself can lead to kidney disease development. Further studies are required to better understand the association between obesity and kidney disease.

Keywords: obesity; overweight; kidney failure, chronic.

\section{INTRODUCTION}

Chronic kidney disease (CKD) is currently a worldwide public health problem that increasingly affects individuals early in their productive years and brings negative consequences for quality of life. There is evidence that CKD is an independent risk factor for angina, acute myocardial infarction, heart failure, stroke, peripheral vascular disease and arrhythmias., ${ }^{1,2}$

\section{Resumo}

Obesidade tem sido apontada como uma importante causa de doenças renais, incluindo a doença renal crônica (DRC). A obesidade influencia o desenvolvimento de DRC, entre outros fatores, porque predispõe à nefropatia diabética, nefroesclerose hipertensiva e glomeruloesclerose segmentar e focal. O excesso de peso e a obesidade estão associados a alterações renais hemodinâmicas, estruturais e histológicas, além de alterações metabólicas e bioquímicas que levam à doença renal. O tecido adiposo é dinâmico e está envolvido na produção de "adipocinas", como a leptina, adipnectina, fator de necrose tumoral- $\alpha$, proteína quimiotática de monócitos-1, fator de transformação do crescimento- $\beta$ e angiotensina-II. Uma série de eventos é desencadeada pela obesidade, incluindo resistência à insulina, intolerância à glicose, dislipidemia, aterosclerose e hipertensão. Há evidência de que a obesidade por si só pode levar ao desenvolvimento de doença renal. Mais estudos são necessários para melhor entender a associação entre obesidade e doença renal.

Palavras-chave: obesidade; sobrepeso; falência renal crônica.

The incidence and prevalence of CKD are growing and are associated to the increase in the population's life expectancy and the number of cases of systemic arterial hypertension (SAH) and diabetes mellitus (DM), the main causes of CKD. ${ }^{3,4}$ Approximately $13 \%$ of the adult US population has CKD stages 1 to 4. ${ }^{5}$ In Brazil, the incidence and prevalence of CKD are not known, but it is estimated 
that currently more than 100,000 Brazilian individuals are undergoing dialysis. ${ }^{6}$

Obesity has been identified as a major cause of kidney disease, including $\mathrm{CKD}^{7-9}$ with evidence of causality in several studies. ${ }^{3,7,10-12}$ Due to the close association with DM and hypertension, overweight and obesity, which show epidemic proportions worldwide, ${ }^{13}$ are important risk factors for CKD onset, especially in adults. Dietary aspects, including some dietary patterns have also been identified as possible risk factors for CKD. ${ }^{14}$

Obesity influences the development of CKD, among other factors, by predisposing to diabetic nephropathy, hypertensive nephrosclerosis and focal and segmental glomerulosclerosis., ${ }^{3,8}$ Considering the growing trend of excess weight, which already affected half of the Brazilian population in 2013, according to the results of the latest telephone survey, VIGITEL, ${ }^{15}$ an increase in the number of CKD cases is expected. In a multicentric cohort study (ELSA-Brasil), which included 15,105 Brazilian adults, the observed rate of excess weight was high, affecting $65.9 \%$ of men and $60.8 \%$ of women. ${ }^{16}$

This article discusses the pathophysiology aspects of the association between obesity and kidney disease, discussing the most important aspects and the most current evidence of this association.

\section{EPIDEMIOLOGICAL ASPECTS OF OBESITY, METABOLIC SYNDROME AND KIDNEY DISEASE}

Overweight and obesity have increased incidence and prevalence worldwide. In the United States, it is estimated that one third of adults are overweight and one third are obese. ${ }^{13}$ Several studies have shown a significant association between obesity and kidney disease. .,3,10-12 $^{2}$ Currently, an epidemic of both overweight and obesity, as well as of chronic kidney disease can be observed and these conditions may be associated. ${ }^{13}$

In the last 15 years, a steady increase in the number of obese patients undergoing dialysis has been observed. ${ }^{17}$ There is also evidence that high levels of serum creatinine are associated with an increased risk of metabolic syndrome (MS). ${ }^{18}$ Moreover, there is evidence that obesity, especially when present in the early years of adulthood, is a risk factor for the development of renal carcinoma. ${ }^{8}$ An association between obesity and nephrolithiasis has also been described, particularly uric acid and calcium oxalate calculi. ${ }^{8,9}$
The association between increased waist circumference, high blood pressure, high fasting glucose and dyslipidemia constitutes the condition known as metabolic syndrome, which is associated with high cardiovascular risk. ${ }^{19-21}$ The role of MS as a cause of CKD has been little discussed, although it is a major cause of hypertension and diabetes mellitus, conditions that account for over $70 \%$ of cases of CKD. ${ }^{7}$ Individuals with MS have a 2-to-3 fold higher risk of developing microalbuminuria than those without MS.22

There is evidence that all MS components show a significant association with CKD. ${ }^{11,12}$ In a longitudinal study of 3,437 individuals from South Korea, CKD was associated with MS, irrespective of body weight and obesity was associated with $\mathrm{CKD}$, regardless of the presence of MS. ${ }^{12}$ Waist circumference and other components of MS have shown an independent association with CKD. ${ }^{3}$

There is a positive association between the number of MS components and the risk of CKD. ${ }^{22}$ Central obesity seems to be more important than body mass index (BMI) as a risk factor for cardiovascular diseases and $\mathrm{CKD}^{8}$. Several renal disorders are associated with overweight, obesity and metabolic syndrome, as summarized in Table 1.

\section{Pathophysiology of obesity leading to KIDNEY DISEASE}

Overweight and obesity are associated with hemodynamic, structural and histopathological alterations in the kidney, as well as metabolic and biochemical alterations that predispose to kidney disease, even when renal function is normal in the conventional tests. ${ }^{8,23}$ It is currently known that adipose tissue is not only a fat reservoir, but a dynamic tissue involved in the production of "adipokines", such as leptin, adiponectin, tumor necrosis factor- $\alpha$, monocyte chemoattractant protein-1, transforming growth factor- $\beta$ and angiotensin-II. ${ }^{23}$

A series of events is triggered by obesity, including insulin resistance, glucose intolerance, hyperlipidemia, atherosclerosis and hypertension, all of which are associated with increased cardiovascular risk. The association between CKD and dyslipidemia has also been described, but its causes are still unknown. Insulin action resistance, present in $\mathrm{CKD}$, reduces the activity of lipoprotein lipase, which may be implicated in the pathophysiology of dyslipidemia in CKD. ${ }^{24}$ 
Effective plasmatic flow increase

Hemodynamic/Physiologic changes

\begin{tabular}{ll} 
& Filtration fraction increase \\
& Magnitude increase of albuminuria/proteinuria \\
\hline & Kidneys' weight increase \\
& Glomerular surface increase \\
& Glomerulomegaly \\
& Glomerular basement membrane increase \\
& Mesangial matrix expansion \\
& Mesangial cell proliferation \\
& Mesangial cell proliferation \\
Anatomic changes & Decrease in the number of podocytes per glomeruli \\
& Increase in the lenght of podocyte processes \\
\hline Pathology & Increase in the proportional number of glomeruli with segmental and global \\
& sclerosis \\
& Obesity-associated glomerulopathy/FSGS \\
\hline Chronic kidney disease/Glomerulopathies & Diabetic nephropathy \\
& Hypertensive neprhosclerosis \\
& FSGS \\
& IgA nephropathy \\
\hline * GFR: Glomerular Filtration Rate; FSGS = Focal and segmental glomerulosclerosos. Adapted from Kopple \& Feroze, 2011. & Higher incidence of renal carcinoma \\
& Higher incidence of nephrolithiasis (uric acid and calcium oxalate) \\
& Higher incidence of surgical complications and graft loss in the context of \\
& kidney transplantation \\
\hline Other renal/urologic complications & Higher incidence of ESRD \\
\hline &
\end{tabular}

Obesity leads to increased renal tubular sodium reabsorption, impairing pressure natriuresis and causing volume expansion due to the activation of the sympathetic nervous system (SNS) and the reninangiotensin-aldosterone system (RAAS). Compression also occurs in the kidneys, especially when visceral obesity is presente..$^{3,7,8}$

The increase in sodium reabsorption and consequent extracellular volume expansion is a central event in the development of SAH in obesity. Some evidence suggests that an increase in sodium reabsorption occurs in some segments in addition to the proximal tubule, possibly in the loop of Henle. ${ }^{7}$ Also, there is an increase in renal blood flow, glomerular filtration rate (GFR) and filtration fraction.

Glomerular hyperfiltration, associated with increased blood pressure and other metabolic alterations such as insulin resistance and DM, finally result in kidney damage and reduced GFR ${ }^{3,7,8}$. The sympathetic nervous system (SNS) activation also contributes to obesity-related hypertension. There is evidence that renal denervation reduces sodium retention and hypertension in obesity, suggesting that SNS activation induced by obesity increases blood pressure mainly due to the sodium retention stimulus, rather than vasoconstriction.

The mechanisms that lead to SNS activation in obesity are not yet fully understood, but several factors have been proposed as triggers for this stimulus, including hyperinsulinemia, hyperleptinemia, increased levels of fatty acids, angiotensin II levels and baroreceptor reflex alterations. ${ }^{3,7,8}$ The increase in leptin levels is associated with SNS activation and its effect on blood pressure level increase also includes nitric oxide synthesis inhibition (potent vasodilator).

An increased production of endothelin-1 has also been described in obese subjects, which further contributes to the elevation of blood pressure levels and consequently to renal dysfunction. ${ }^{3}$ Recent studies have shown that endothelin-1 is increased in patients with intradialytic hypertension, ${ }^{25}$ suggesting 
that this substance plays a key role in the genesis of hypertension in patients with CKD and is possibly associated with hypertension in obese patients.

Adipose tissue accumulation, especially in visceral adiposity, causes kidney compression, and a consequent increase in intrarenal pressure. The excess of retroperitoneal adipose tissue involves the kidneys and penetrates the renal hilum up to the medulla, causing compression of the renal medulla and increased hydrostatic pressure of the renal interstitial fluid. Excess visceral fat also increases the intra-abdominal pressure, causing further renal compression., ${ }^{3,8}$ The physical compression of the kidney causes increased extracellular matrix formation in the renal medulla. As the kidneys are surrounded by a capsule, which has low compliance, extracellular matrix accumulation can further exacerbate intrarenal compression and increase the hydrostatic pressure of the interstitial fluid.

This increase in intrarenal pressure, in turn, compresses the loop of Henle and peritubular capillaries (vasa recta), which reduces the flow of fluids through the renal tubules leading to sodium reabsorption by them. $3,7,8$

Another important factor in the pathophysiology of obesity renal complications is the so-called "lipotoxicity", which refers to the disorders caused by the exacerbated metabolism of fatty acids in nonadipose tissue, such as skeletal muscle, pancreatic islets, myocardium and possibly the kidneys.

In "overnutrition" states, the supply of fatty acids to the tissues exceeds the metabolic needs, leading to a compensatory increase in their oxidation. The increase in fatty acid metabolism leads to the production and release of several substances harmful to the cells, such as the products of lipid peroxidation and triglycerides, which can induce apoptosis and fibrosis in non-adipose tissues. $3,7,8$

Obesity is also associated with inflammation, as an increase in the production of inflammatory cytokines such as tumor necrosis factor- $\alpha$, interleukin- 6 and C-reactive protein can be observed, being called "adipokines" by some authors because of their production by adipocytes. Inflammation itself is a risk factor for renal function loss. ${ }^{26,27}$ Renal fibrosis (interstitial and glomerular), in addition to the irreversible accumulation of extracellular matrix in kidney tissue, is associated with inflammation, processes that may be associated with the "adipokines". 3,8

There is also evidence that obesity itself increases albumin excretion, which progressively increases with obesity severity and, in rare cases, can lead to nephrotic syndrome. ${ }^{7}$ Obesity has also shown to be an important risk factor for renal disease progression in patients with glomerulopathies, such as in IgA nephropathy. ${ }^{28}$

Focal and segmental glomerulosclerosis (FSGS) is the type of glomerulonephritis most often associated with obesity. ${ }^{29}$ FSGS associated with obesity typically presents with nephrotic syndrome and progressive renal function loss. The morphological findings include glomerulomegaly, predominance of perihilar variant and mild podocyte fusion..$^{29}$ Weight loss, either by dieting or through bariatric surgery, leads to proteinuria reduction. ${ }^{8}$

The association between obesity, MS and nephrolithiasis has been observed in some studies, mainly due to increased serum uric acid levels in obese individuals. ${ }^{30}$

Although obesity represents a major risk factor for the development of cardiovascular disease, some studies have shown that obesity is a protective factor in individuals with end-stage CKD (undergoing dialysis),, 31 perhaps because malnutrition is associated with higher mortality when compared to obesity. However, even in patients undergoing dialysis, visceral obesity is associated with increased risk of coronary calcification and adverse cardiovascular events. ${ }^{17}$ The pathophysiology of obesityrelated kidney disease is shown in Figure 1.

Figure 1. Pathophysiology of the association between obesity and kidney disease. Adapted from Silva Junior \& Matos, 2016.

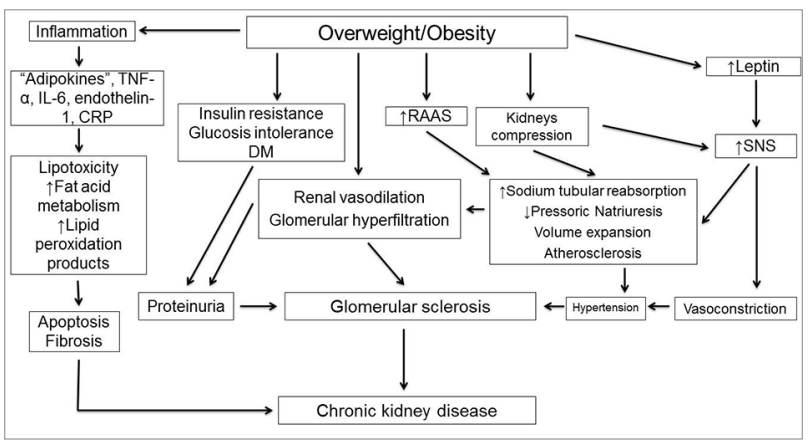

\section{Conclusion}

The incidence of obesity has been increasing worldwide and is an important risk factor for kidney disease. There is evidence that obesity alone can lead to the development of kidney diseases, including chronic kidney disease, glomerulopathy and nephrolithiasis. The pathophysiology of obesity-related kidney disease includes anatomic and hemodynamic alterations in the renal system. More studies are required to better understand the association between obesity and kidney disease. 


\section{REFERENCES}

1. Chronic Kidney Disease Prognosis Consortium, Matsushita K, van der Velde M, Astor BC, Woodward M, Levey AS, de Jong PE, et al. Association of estimated glomerular filtration rate and albuminuria with all-cause and cardiovascular mortality in general population cohorts: a collaborative meta-analysis. Lancet 2010;375:2073-81. PMID: 20483451 DOI: http:// dx.doi.org/10.1016/S0140-6736(10)60674-5

2. Gansevoort RT, Correa-Rotter R, Hemmelgarn BR, Jafar TH, Heerspink HJ, Mann JF, et al. Chronic kidney disease and cardiovascular risk: epidemiology, mechanisms, and prevention. Lancet 2013;382:339-52. PMID: 23727170 DOI: http://dx.doi.org/10.1016/S0140-6736(13)60595-4

3. Kopple JD. Obesity and chronic kidney disease. J Ren Nutr 2010;20:S29-S30. DOI: http://dx.doi.org/10.1053/j. jrn.2010.05.008

4. Ecder T. Early diagnosis saves life: focus on patients with chronic kidney disease. Kidney Int Suppl 2013;3:335-6. DOI: http://dx.doi.org/10.1038/kisup.2013.70

5. Centers for Disease Control and Prevention (CDC). Prevalence of chronic kidney disease and associated risk factorsUnited States, 1999-2004. MMWR Morb Mortal Wkly Rep 2007;56:161-5. PMID: 17332726

6. Sesso RC, Lopes AA, Thomé FS, Lugon JR, Watanabe Y, Santos DR. Relatório do Censo Brasileiro de Diálise Crônica 2012. J Bras Nefrol 2014;36:48-53. DOI: http://dx.doi. org/10.5935/0101-2800.20140009

7. Hall JE, Henegar JR, Dwyer TM, Liu J, Silva AA, Kuo JJ, et al. Is obesity a major cause of chronic kidney disease? Adv Ren Replace Ther 2004;11:41-54.

8. Kopple JD, Feroze U. The effect of obesity on chronic kidney disease. J Ren Nutr 2011;21:66-71. DOI: http://dx.doi. org/10.1053/j.jrn.2010.10.009

9. Taylor EN, Stampfer MJ, Curhan GC. Obesity, weight gain, and the risk of kidney stones. JAMA 2005;293:455-62. PMID: 15671430 DOI: http://dx.doi.org/10.1001/jama.293.4.455

10. Chang A, van Horn L, Jacobs DR Jr, Liu K, Muntner P, Newsome B, et al. Lifestyle-related factors, obesity, and incident microalbuminuria: The CARDIA (Coronary Artery Risk Development in Young Adults) study. Am J Kidney Dis 2013;62:267-75. DOI: http://dx.doi.org/10.1053/j. ajkd.2013.02.363

11. Lee KB, Hyun YY, Kim H. DASH dietary pattern and chronic kidney disease in elderly Korean population. Nephrol Dial Transplant 2015;30:iii504-iii505.

12. Song YM, Sung J, Lee K. Longitudinal relationships of metabolic syndrome and obesity with kidney function: Healthy Twin Study. Clin Exp Nephrol 2015;19:887-94. DOI: http:// dx.doi.org/10.1007/s10157-015-1083-5

13. Hariharan D, Vellanki K, Kramer H. The Western Diet and Chronic Kidney Disease. Curr Hypertens Rep 2015;17:16. DOI: http://dx.doi.org/10.1007/s11906-014-0529-6

14. Silva Junior, Matos SMA. Padrões alimentares e doença renal crônica. In Cruz J, Cruz HMM, Kirsztajn GM, Oliveira RB, Barros RT, eds. Atualidades em Nefrologia 14. São Paulo: Sarvier; 2016.

15. Brasil. Ministério da Saúde. Secretaria de Atenção à Saúde. VIGITEL Brasil 2013. Vigilância de fatores de risco para doenças crônicas por inquérito telefônico. Brasília: Ministério da Saúde; 2014

16. Schmidt MI, Duncan BB, Mill JG, Lotufo PA, Chor D, Barreto SM, et al. Cohort Profile: Longitudinal Study of Adult Health (ELSA-Brasil). Int J Epidemiol 2014;44:68-75. PMID: 24585730 DOI: http://dx.doi.org/10.1093/ije/dyu027

17. Johansen KL, Lee C. Body composition in chronic kidney disease. Curr Opin Nephrol Hypertens 2015;24:268-75.
18. Wang J, Li X, Han X, Yang K, Liu B, Li Y, et al. Serum creatinine levels and risk of metabolic syndrome in a middle-aged and older Chinese population. Clin Chim Acta 2015;440:177-82. DOI: http://dx.doi.org/10.1016/j.cca.2014.11.025

19. Alberti KG, Eckel RH, Grundy SM, Zimmet PZ, Cleeman JI, Donato KA, et al.; International Diabetes Federation Task Force on Epidemiology and Prevention; Hational Heart, Lung, and Blood Institute; American Heart Association; World Heart Federation; International Atherosclerosis Society; International Association for the Study of Obesity. Harmonizing the metabolic syndrome: a joint interim statement of the International Diabetes Federation Task Force on Epidemiology and Prevention; National Heart, Lung, and Blood Institute; American Heart Association; World Heart Federation; International Atherosclerosis Society; and International Association for the Study of Obesity. Circulation 2009;120:1640-5. PMID: 19805654 DOI: http://dx.doi. org/10.1161/CIRCULATIONAHA.109.192644

20. Abd Elaziz KM, Gabal MS, Aldafrawy OA, Abou Seif HA, Allam MF. Prevalence of metabolic syndrome and cardiovascular risk factors among voluntary screened middle-aged and elderly Egyptians. J Public Health (Oxf) 2015;37:612-7.

21. Kul S, Uyarel H, Gul M, Kucukdagli OT, Bacaksiz A, Erdogan E, et al. Metabolic syndrome and long-term cardiovascular outcomes in NSTEMI with unstable angina. Nutr Metab Cardiovasc Dis 2014;24:176-82. DOI: http://dx.doi. org/10.1016/j.numecd.2013.07.003

22. Bi H, Wu Y, Zhao C, Long G. Association between the dietary factors and metabolic syndrome with chronic kidney disease in Chinese adults. Int J Clin Exp Med 2014;7:4448-54.

23. Declèves AE, Sharma K. Obesity and kidney disease: differential effects of obesity on adipose tissue and kidney inflammation and fibrosis. Curr Opin Nephrol Hypertens 2015;24:28-36. DOI: http://dx.doi.org/10.1097/MNH.0000000000000087

24. Avesani CM, Pereira AML, Cuppari L. Doença renal crônica. In: Cuppari L, ed. Nutrição nas doenças crônicas nãotransmissíveis. Barueri: Manole; 2009. p. 267-330.

25. Gutiérrez-Adrianzén OA, Moraes ME, Almeida AP, Lima JW, Marinho MF, Marques AL, et al. Pathophysiological, cardiovascular and neuroendocrine changes in hypertensive patients during the hemodialysis session. J Hum Hypertens 2015;29:366-72. DOI: http://dx.doi.org/10.1038/jhh.2014.93

26. Bash LD, Erlinger TP, Coresh J, Marsh-Manzi J, Folsom AR, Astor BC. Inflammation, hemostasis, and the risk of kidney function decline in the Atherosclerosis Risk in Communities (ARIC) Study. Am J Kidney Dis 2009;53:596-605. DOI: http:// dx.doi.org/10.1053/j.ajkd.2008.10.044

27. Lin J, Hu FB, Mantzoros C, Curhan GC. Lipid and inflammatory biomarkers and kidney function decline in type 2 diabetes. Diabetologia 2010;53:263-7. PMID: 19921505 DOI: http://dx.doi.org/10.1007/s00125-009-1597-z

28. Praga M, Hernández E, Herrero JC, Morales E, Revilla Y, Díaz-González R, et al. Influence of obesity on the appearance of proteinuria and renal insufficiency after unilateral nephrectomy. Kidney Int 2000;58:2111-8. PMID: 11044232 DOI: http://dx.doi.org/10.1111/j.1523-1755.2000.00384.x

29. Darouich S, Goucha R, Jaafoura MH, Zekri S, Ben Maiz H, Kheder A. Clinicopathological characteristics of obesity-associated focal segmental glomerulosclerosis. Ultrastruct Pathol 2011;35:176-82. DOI: http://dx.doi.org/10.3109/01913123.2011.584657

30. Wong YV, Cook P, Somani BK. The association of metabolic syndrome and urolithiasis. Int J Endocrinol 2015;2015:570674. PMID: 25873954 DOI: http://dx.doi.org/10.1155/2015/570674

31. Park J, Ahmadi SF, Streja E, Molnar MZ, Flegal KM, Gillen $\mathrm{D}$, et al. Obesity paradox in end-stage kidney disease patients. Prog Cardiovasc Dis 2014;56:415-25. DOI: http://dx.doi. org/10.1016/j.pcad.2013.10.005 